Original Paper http://ajol.info/index.php/ijbcs http://indexmedicus.afro.who.int

\title{
Shell of balanites egyptiacas to effectively eliminate arsenate of aqueous solutions
}

\author{
Marou GOUROUZA ${ }^{1}$, Zeinabou MAHAMADOU ${ }^{1 *}$ and Anne BOOS ${ }^{2}$ \\ ${ }^{I}$ Materials, Water and Envirronment Laboratory, Abdou Moumouni University, BP 10662, Niamey, Niger. \\ ${ }^{2}$ Analytical Laboratory, School of Chemistry of Polymers and Materials, Louis Pasteur University, Strasbourg, \\ France. \\ *Corresponding author ; E-mail : diopdoudou@hotmail.com
}

\begin{abstract}
The objective of this study is the search for an adsorbent capable of removing arsenate from aqueous solutions, which can be expensive and accessible. Thus, balanite oegyptiaca shell activated carbon (CBCA) has been tested as an adsorbent for removal of arsenate ions. The effects of some experimental parameters such as contact time and solution $\mathrm{pH}$ on As (V) removal were investigated via batch experiments. Isotherms and adsorption kinetics have been discussed to study the effectiveness of the adsorbent. With an initial concentration of $10 \mathrm{mg} / \mathrm{L}$ of the As (V) solution, the adsorption equilibrium is reached in less than 120 minutes. The adsorption isotherms were well described by the Langmuir model and the adsorption capacity was $260 \mu \mathrm{g} / \mathrm{g}$ at $\mathrm{pH} 7$ for CBCA. The adsorption kinetics was well adapted by the pseudo-second order model, and intraparticle diffusion was not the only limiting step in the adsorption process. Considering the Balanite oegyptiaca as waste biomass material, the biosorbent (CBCA) is promising to be exploited for applications in the treatment polluted waters containing a certain ratio of arsenic.
\end{abstract}

(C) 2018 International Formulae Group. All rights reserved.

Keywords: Arsenic adsorption, isotherm, kinetics, balanite oegyptiaca.

\section{INTRODUCTION}

Arsenic is about $0.00015 \%$ of the earth's crust in the form of more than 300 minerals, making it the 53rd most abundant element (Emsley, 2001). Soluble arsenic exists as two predominant inorganic species: arsenite As (III) $\left(\mathrm{H}_{2} \mathrm{AsO}_{3}^{-}, \mathrm{HAsO}_{3}^{2-}\right.$ and $\left.\mathrm{AsO}_{3}{ }^{3-}\right)$ and arsenate $\mathrm{As}(\mathrm{V})\left(\mathrm{H}_{2} \mathrm{AsO}_{4}^{-}\right.$, $\mathrm{HAsO}_{4}{ }^{2-}$ and $\mathrm{AsO}_{4}{ }^{3-}$ ) (Shan and Tong, 2013; Yang el al., 2015). Arsenic is one of the most toxic chemical elements and arsenic contamination is considered to be one of the most serious environmental problems (Chandra, 2010). Long-term exposure and ingestion of arsenic-contaminated water can lead to serious health problems such as skin lesions, kidney failure and cancer (Luo et al., 2012). Arsenic poisoning also affects the functioning of the nervous and cardiovascular system and even leads to death (Andjelkovic et al., 2015). The World Health Organization (WHO) has set a maximum limit of $10 \mathrm{ppb}$ for arsenic in drinking water, which was subsequently adopted by the United States, the European Union and China (Guo et al., 2012). Adsorption is considered one of the most promising technologies for arsenic remediation as it is: simple to use, versatile, 
$\mathrm{pH}$ tolerant, low cost, therefore cost effective compared with other methods such as coagulation, reverse osmosis and biological treatment ( Ma and Zhang, 2008; Salameh et al., 2015). Most of these technologies, with the exception of adsorption, have certain disadvantages such as high cost, long service life, sophisticated instrumentation requirements and high energy consumption. For developing countries, including Niger, adsorption is the most appropriate method that involves the least instrumentation and the availability of a wide range of pollutantspecific adsorbents (Ali, 2012; Saha and Sarkar, 2012). A number of materials have been extensively studied, but activated carbon is widely used as an adsorbent worldwide for the removal of various pollutants (Ahmed and Ahmaruzzaman, 2016). Indeed, activated carbon has a high specific surface area, mechanical stability and surface functional groups that could provide good support for adsorption (Ghanizadeh et al., 2010). In Niger, the local agro-food industry produces large stocks of waste that can be used for water treatment. This is the case for example hulls of Balanites oegyptiaca. This material is inexpensive, very available both in terms of quantities and proximity to the regions of the water to be treated. The objectives of this work were (i) preparation of adsorbents from the shell of calcined (CBC) or calcined and activated (CBCA) Balanites oegyptiaca; (ii) thermodynamics, kinetics, adsorption capacity; (iii) mechanism of adsorption of arsenates on CBCA. Adsorption isotherms and kinetics have been discussed to study the effectiveness of the adsorbent.

\section{MATERIALS AND METHODS Preparation of the absorbent}

The adsorbent is obtained from a natural waste (the shell of balanites oegyptiaca (CB)). The $\mathrm{CB}$ was calcined at 700 ${ }^{\circ} \mathrm{C}$ and then activated with $3 \mathrm{M}$ hydrochloric $\operatorname{acid}(\mathrm{HCl})$.

\section{Optimization of adsorption parameters}

The influence of the calcination temperature $\left(400{ }^{\circ} \mathrm{C}, 500{ }^{\circ} \mathrm{C}, 600{ }^{\circ} \mathrm{C}\right.$ and 700 $\left.{ }^{\circ} \mathrm{C}\right)$, the concentration of the acid used $(0.5 \mathrm{M}$, $1 \mathrm{M}, 2 \mathrm{M}$ and $3 \mathrm{M}$ ) and the $\mathrm{pH}$ of the adsorbed solution (2-10) have been studied. The effect on the adsorption capacity of the solids of the mass of the adsorbent ( 4 to $20 \mathrm{~g} / \mathrm{L}$ ) was studied. The contact time required to reach equilibrium was determined using different contact times (15, 30, 45, 60, 75 and $90 \mathrm{~min})$. To check the sensitivity of the supports to the presence of other anions, adsorption were carried out in the presence of competing anions $\left(\mathrm{Cl}^{-}, \mathrm{NO}_{3}{ }^{-}, \mathrm{SO}_{4}{ }^{2-}\right)$ using different concentrations $(10,20,30$ and $40 \mathrm{mg} / \mathrm{L})$ of the competing anion. Finally, the influence of the temperature of the experiment on the percentage of extraction of F-ions by the solid CBCA was studied, carrying out the adsorption at three different temperatures (298K, 318K and 323K).

\section{Physico-chemical characteristics of the adsorbent}

The nitrogen adsorption / desorption isotherms were carried out with an ASAP $2420 \mathrm{~V} 2.09$ (V2.09 J) at $77 \mathrm{~K}$, with degassing at $393 \mathrm{~K}$ before the measurements. The BET method (Brunauer-Emmett-Teller) was used to calculate the specific surface area. The pore size distribution (PSD) and pore volume (PV) were derived from desorption branches of the isotherms using the Barrett-Joyner-Halenda (BJH) model. The concept of PZC suggests the availability of $\mathrm{OH}-(\mathrm{pH}>\mathrm{PZC})$ or $\mathrm{H}+$ ions ( $\mathrm{pH}<\mathrm{PZC}$ ) on the surface of the adsorbent. CBCA PZC was determined by the salt addition method as indicated in the literature (Velazquez-Peña et al., 2017). Briefly, $50 \mathrm{ml}$ of $0.1 \mathrm{M}$ solution of $\mathrm{KNO}_{3}$ was transferred to six $100 \mathrm{ml}$ Erlenmeyer flasks. The initial $\mathrm{pH}$ of these solutions was adjusted to 2.0, 4.0, 6.0, 8.0, 10 and 12 by adding $0.1 \mathrm{M} \mathrm{HNO}_{3} / \mathrm{NaOH}$ and then $200 \mathrm{mg}$ CBCA was added to each vial. These flasks were stirred in a water bath for $2 \mathrm{~h}$ at room temperature and allowed to equilibrate for $48 \mathrm{~h}$. The suspensions were centrifuged and the final $\mathrm{pH}$ of each supernatant was noted. The CBCA PZC was calculated from the curve between the initial 
$\mathrm{pH}$ and the final $\mathrm{pH}$. The point at which the final $\mathrm{pH}$ curve crosses the initial $\mathrm{pH}$ gave PZC. Since functional groups at the surface of carbon-based materials play important roles during the adsorption process, the FTIR analysis of CBCA was performed. Two infrared Fourier Transform (FT-IR) spectra of the adsorbent before and after adsorption were recorded to monitor changes in the functional groups of the samples on a PERKIN ELMER Universal ATR (Attenuated Total Reflectance) spectrometer over a spectral range of $500-4000 \mathrm{~cm}^{-1}$.

\section{Adsorption experiments}

The reagent used was $\mathrm{Na}_{2} \mathrm{HAsO}_{4}$, $7 \mathrm{H}_{2} \mathrm{O}$ (Sigma-Aldrich) of high analytical quality. The stock solution As (V) was prepared with $\mathrm{Na}_{2} \mathrm{HA} 5,4,7 \mathrm{H}_{2} \mathrm{O}$ (SigmaAldrich) and ultrapure water. Batch experiments were performed in polyethylene vials $(40 \mathrm{ml}$ ) containing $20 \mathrm{ml}$ of As (V) solution with the required concentrations and the dose of CBCA. To evaluate the adsorption performance and isotherms of the adsorbent, $0.08 \mathrm{~g}$ samples were added in $20 \mathrm{ml}$ of As (V) solutions of $1,2,4,8$, and $10 \mathrm{mLL}^{-1}$. Kinetic studies were performed at time intervals of 15 min to $2 \mathrm{~h}$ with solutions of $4 \mathrm{mg} \mathrm{L}^{-1}$ of As (V) and $4 \mathrm{gL}^{-1}$ of CBCA. The mixture (adsorbent-solution As (V)) is stirred at 200 rpm for a time t. after adsorption, the aqueous samples were filtered by centrifugation at $1300 \mathrm{rpm}$, and the residual arsenic concentrations were measured by inductively coupled plasma optical emission spectrometry (ICP-OES, Agilent 720ES, USA) . The adsorption capacity (qe) was calculated as the amount of adsorbed arsenic per unit mass of CBCA.

$\boldsymbol{q}_{e}=\frac{\left(\mathrm{C}_{\mathbf{0}}-\mathbf{C e}\right) \mathbf{V}}{\mathbf{m}}$

Where Co $\left(\mathrm{mg} \cdot \mathrm{L}^{-1}\right)$ is the initial concentration of As (V) and Ce (mg. $\left.\mathrm{L}^{-1}\right)$ the concentration $\mathrm{As}(\mathrm{V})$ at equilibrium; $\mathrm{m}(\mathrm{g})$ is the mass of CBCA used; $\mathrm{V}(\mathrm{L})$ is the volume of the solution of As (V).

\section{Adsorption isotherms and kinetic adsorption studies}

There are several equations of isotherms available to analyze the experimental data of the adsorption equilibrium. In this study, the Langmuir, Freundlich, Elovich isotherms as well as the first, Lagergren pseudo-second order and interparticle scattering were used to interpret the experimental data of the adsorption process.

\section{RESULTATS \\ Physico-chemical characteristics}

The texture parameters of the $700{ }^{\circ} \mathrm{C}$ calcined flask of Balanites calculated from the $\mathrm{N} 2$ adsorption isotherms at $-196{ }^{\circ} \mathrm{C}$ are: BET Surface $($ SBET $)=167 \mathrm{~m}^{2} / \mathrm{g}$; pore volume $(\mathrm{Vt})=0.093 \mathrm{~cm}^{3} / \mathrm{g}$; micropore volume $(\mathrm{vDR})=0.052 \mathrm{cc} / \mathrm{g}$; mesopore volume $(\mathrm{vMes})=\mathrm{vt}-\mathrm{vDR}=0.041 \mathrm{~cm}^{3} / \mathrm{g} ; \%$ mesopores $=(\mathrm{vMes} / \mathrm{Vt}) * 100=44 ; \%$ micropores $=(\mathrm{vDR} / \mathrm{Vt}) * 100=66 \%$.

The presence of vibration patches at

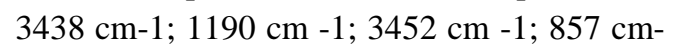
1 before and after adsorption indicate the presence of group $(\mathrm{OH})$. The $1272 \mathrm{~cm}-1$ pick indicates the presence of the $\mathrm{C}-\mathrm{F}$ bond and the $820 \mathrm{~cm}-1$ band indicates the presence of the As-O bond (Zhang et al., 2007; Dharupaneedi et al., 2014).

\section{Arsenic adsorption isotherms and adsorption kinetics Adsorption isotherms}

To evaluate the adsorption capacity of the CBCA, the adsorption isotherms data As (V) were adjusted by both the Langmuir (1) and Freundlich (2) models:

$$
\begin{gathered}
\frac{C e}{q e}=\frac{1}{K L q m}+\frac{C e}{q m} \\
\text { lnqe }=\ln K f+\frac{1}{n} \ln C e
\end{gathered}
$$

Where $\mathrm{Ce}(\mathrm{mg} / \mathrm{L})$ is the equilibrium concentration of arsenic, qe $(\mathrm{mg} / \mathrm{g}$ ) is the adsorption capacity, the parameter qm (mg / g) estimates the maximum adsorption capacity at equilibrium when the adsorbent is saturated 
and the $\mathrm{KL}$ constant $(\mathrm{L} / \mathrm{mg}$ ) is proportional to the adsorption energy (Artioli, 2008). Kf and $1 / \mathrm{n}$ are Freundlich isothermal constants related to adsorption capacity and adsorption intensity, respectively. The constant $\mathrm{Kf}$ in the Freundlich model indicates the adsorption capacity, which is defined as the amount of arsenic adsorbed on the adsorbent at the unit equilibrium concentration. The adsorption isotherms of As (V) on the CBCA are shown in Figure 3. The isothermal constants are listed in Table 1 by nonlinear adjustment.

\section{Kinetics of As (V) adsorption}

Adsorption kinetics is one of the most important parameters for describing adsorption efficiency. In this study, a set of experiments was carried out for adsorbateadsorbent contact times ranging from $15 \mathrm{~min}$ to $130 \mathrm{~min}$, at a constant temperature $\left(25^{\circ} \mathrm{C}\right)$, in order to evaluate the time required to reach the equilibrium and secondly to evaluate the influence of the concentration on the capacity of the adsorption of As (V). As shown in Figures 7, the adsorption balance of As (V) on CBCA can be reached in about 120 minutes. The adsorption capacity of As (V) on CBCA increases gradually with increasing concentration. The adsorption process can be divided into two stages; the adsorption rate was considerably fast in the first 25 minutes, the adsorption rate was slow in the next step. It is further observed that the maximum adsorption capacity of As (V) is about $260 \mu \mathrm{g}$ /g.

In order to better understand the control mechanism of the As (V) adsorption process on CBCA, the pseudo-first order, the pseudo-second order and the intraparticle diffusion rate constant, were studied (Kumar, 2011).

The kinetic models, pseudo-first order and pseudo-second linear, expressed by the equations. (3) and (4) respectively, are used to adjust the experimental data and evaluate the kinetic adsorption process (Min et al., 2015).

$\mathrm{q}_{t}=\mathrm{q}_{e}\left(1-e^{-\mathrm{k}_{1} t}\right)(3)$

$\ln \left(\mathrm{q}_{e}-\mathrm{q}_{t}\right)=\ln \mathrm{q}_{e}-\mathrm{k}_{1} \mathrm{t}(4)$

$\frac{t}{q_{t}}=\frac{1}{k_{2} q_{e}^{2}}+\frac{t}{q_{e}}(5)$

Where qe $(\mathrm{mg} / \mathrm{g})$ and $\mathrm{qt}(\mathrm{mg} / \mathrm{g})$ are the equilibrium and time $\mathrm{t}$ sorption, respectively, and K1 (min-1) and K2 (g.mg-1min-1) are the constants of pseudo-first rate and pseudosecond order adsorption, respectively (Sheha, 2007).

The linear diagrams of pseudo-firstorder and pseudo-second-order kinetic models for As (V) are shown in Figures 5 and 6. The kinetic parameters obtained from pseudo-first order and pseudo-second order for As (V) are summarized in Table 2.

\section{Intraparticle diffusion model}

In order to understand the mechanisms and steps controlling the kinetics of adsorption, the experimental kinetic results were tested by intraparticle diffusion model (Zainab and Hala, 2015) According to this theory.

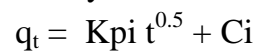

Where $\mathrm{kpi}$ is the intraparticular diffusion rate. $\mathrm{Ci}$, the interception of phase $\mathrm{i}$ gives an idea of the thickness of the boundary layer, that is to say the greater the interception, the greater the effect of the boundary layer is large (Kavitha and Namasivayam, 2007).

The values of $\mathrm{Kp}$ and $\mathrm{Ci}$ are obtained by linearizing the curve $q \mathrm{t}=\mathrm{f}\left(\mathrm{t}^{0.5}\right)$. The values of $\mathrm{Kp}, \mathrm{Ci}$ and the correlation coefficient $\mathrm{R}^{2}$ obtained are in Table 2. The slope of the linear part indicates the rate of the adsorption process (Hameed et al., 2008). The results show that the diffusion rate of As $(\mathrm{v})$ in CBCA decreases as the contact time increases. 
Table 1: Langmuir and Freundlich isotherm parameters of As (V) sorption on CBCA.

\begin{tabular}{|c|c|c|c|c|c|c|c|}
\hline \multirow[t]{2}{*}{ Adsorbent } & \multirow[t]{2}{*}{ adsorbate } & \multicolumn{3}{|c|}{ Freundlich isotherm } & \multicolumn{3}{|c|}{ Langmuir isotherm } \\
\hline & & $\mathrm{K}_{\mathrm{F}}\left(\mathrm{mg} \cdot \mathrm{g}^{-1}\right)$ & $1 / \mathrm{n}$ & $\mathrm{R}^{2}$ & $\mathrm{~K}_{\mathrm{F}}\left(\mathrm{L} \cdot \mathrm{mg}^{-1}\right)$ & $\mathrm{q}_{\mathrm{m}}\left(\mathrm{mg} \cdot \mathrm{g}^{-1}\right)$ & $\mathrm{R}^{2}$ \\
\hline CBCA & $\mathrm{F}^{-}$ & 0,263 & 0,031 & 0,974 & 6,94 & 0,260 & 0,999 \\
\hline
\end{tabular}

Table 2: Kinetic parameters of reaction-based.

\begin{tabular}{|c|c|c|c|c|c|c|c|c|}
\hline \multirow[b]{2}{*}{ Adsorbent } & \multirow[b]{2}{*}{ adsorbate } & \multicolumn{3}{|c|}{ Pseudo-first-order } & \multicolumn{3}{|c|}{ Pseudo-second-order } & Intraparticle diffusion model \\
\hline & & $\begin{array}{l}\mathrm{q}_{\mathrm{e}} \\
(\mathrm{mg} / \mathrm{g})\end{array}$ & $\mathrm{K}_{1}\left(\min ^{-1}\right)$ & $\mathrm{R}^{2}$ & $\begin{array}{l}\mathrm{K}_{2} \\
\left(\mathrm{~g} \cdot \mathrm{mg}^{-}\right. \\
\left.{ }^{1} \mathrm{~min}^{-1}\right)\end{array}$ & $\begin{array}{l}\mathrm{q}_{\mathrm{e}} \\
(\mathrm{mg} / \mathrm{g})\end{array}$ & $\mathrm{R}^{2}$ & $\begin{array}{l}\mathrm{K}_{\mathrm{p}}\left(\mathrm{mgg}^{-1} \min ^{0.5}\right) \\
\mathrm{R}^{2}\end{array}$ \\
\hline CBCA & As $(V)$ & 0,078 & 0,01 & 0,916 & 0,06 & 0,24 & 0,998 & 0,006 \\
\hline
\end{tabular}

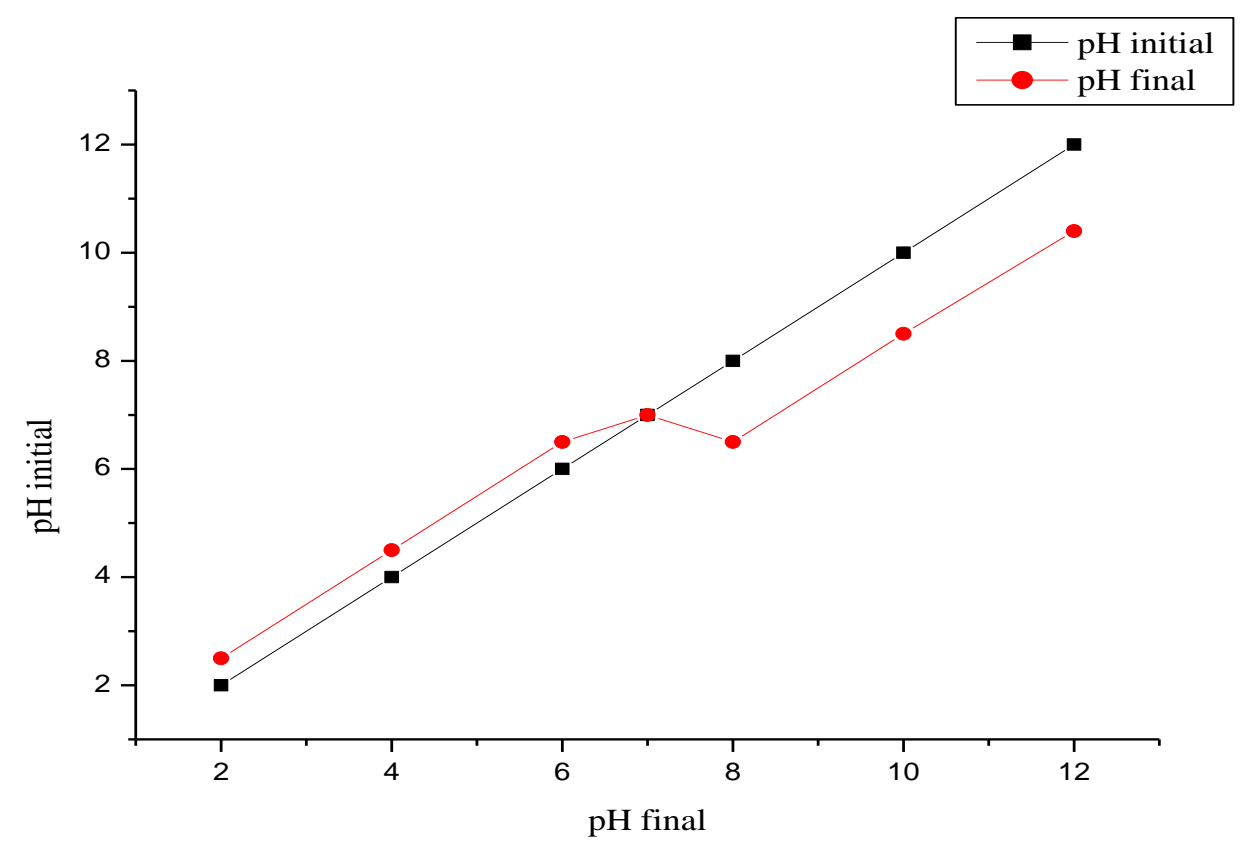

Figure 1: Determination of PZC of the CBCA. 


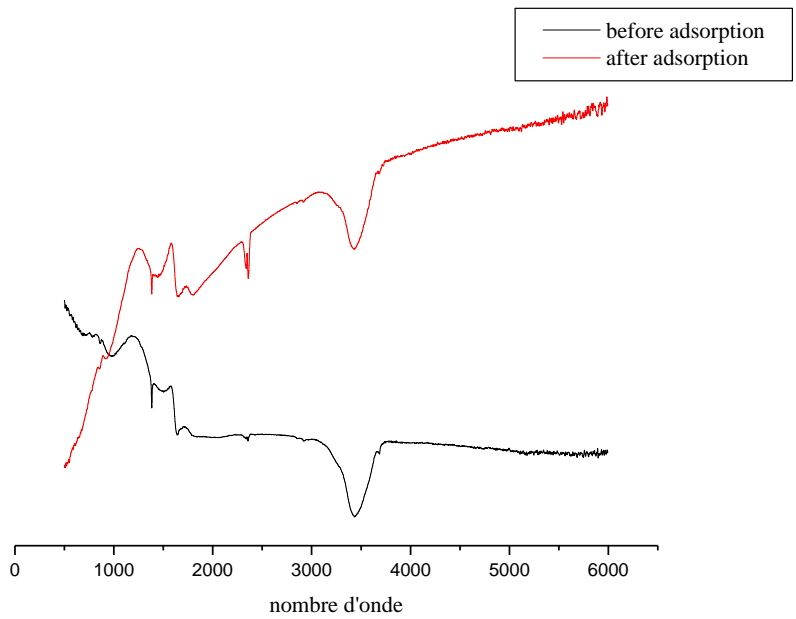

Figure 2: FTIR of CBCA before and after adsorption.

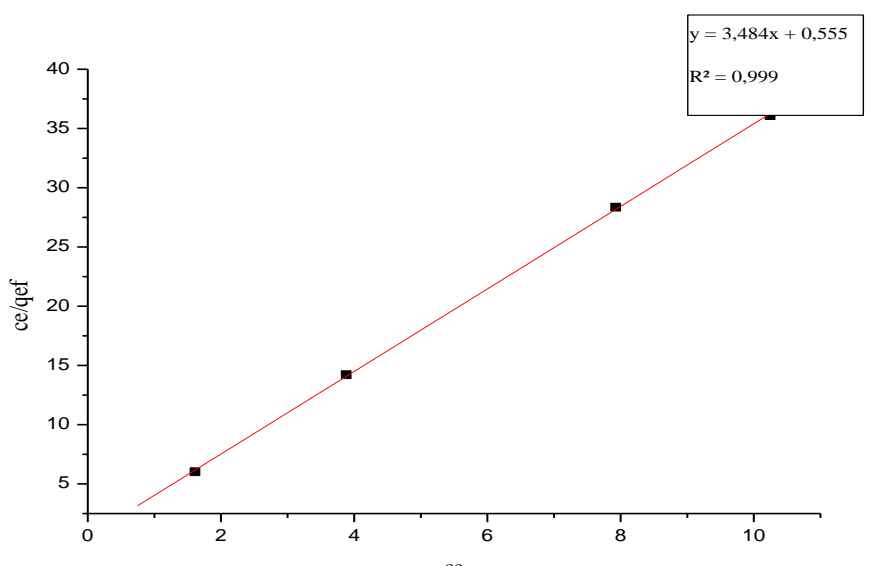

Figure 3: Langmuir isotherm of the adsorption of $\mathrm{F}^{-}$on $\mathrm{CBCA}$.

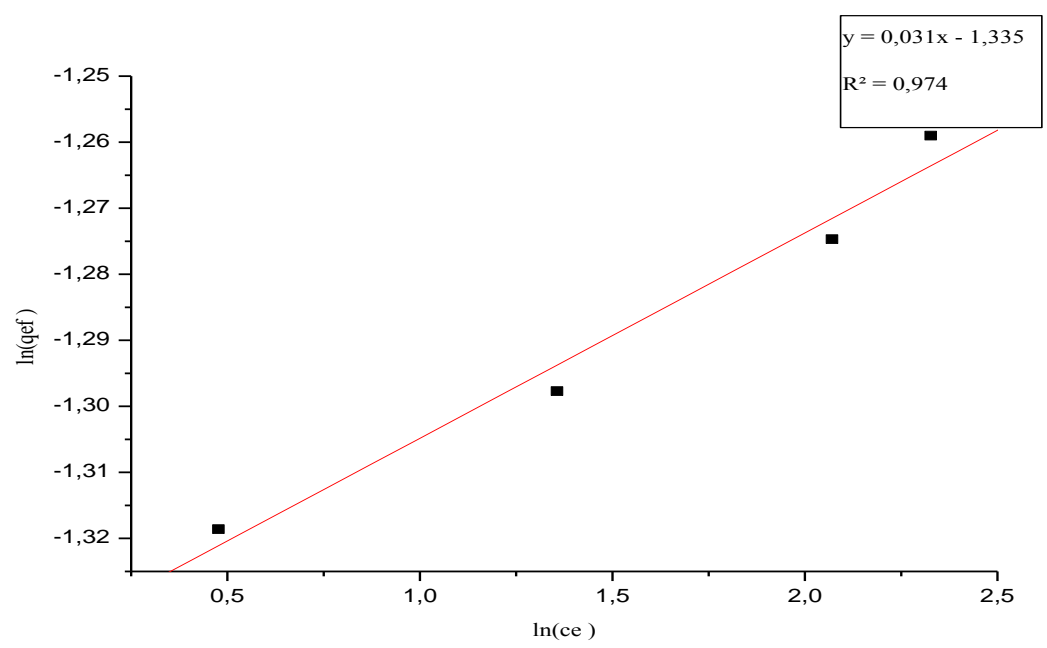

Figure 4: Freundlich isotherm of the adsorption of As (V) on CBCA. 


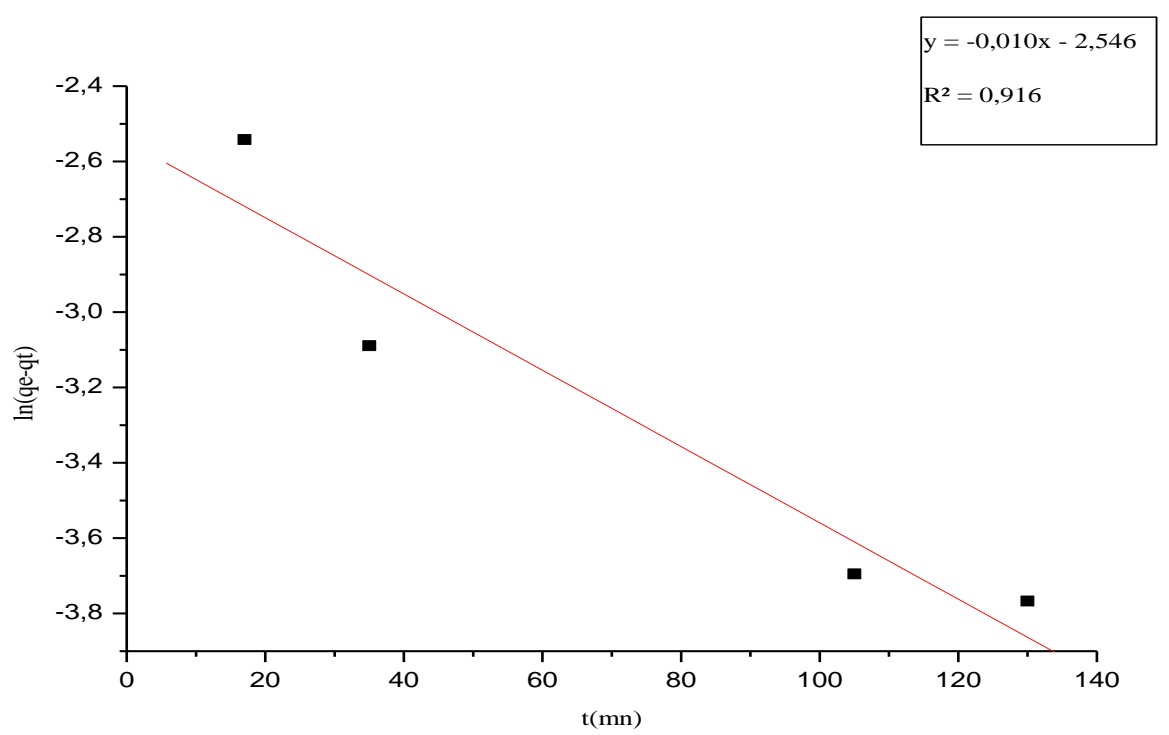

Figure 5: Linear Pseudo first order for adsorption of As (V) using CBCA

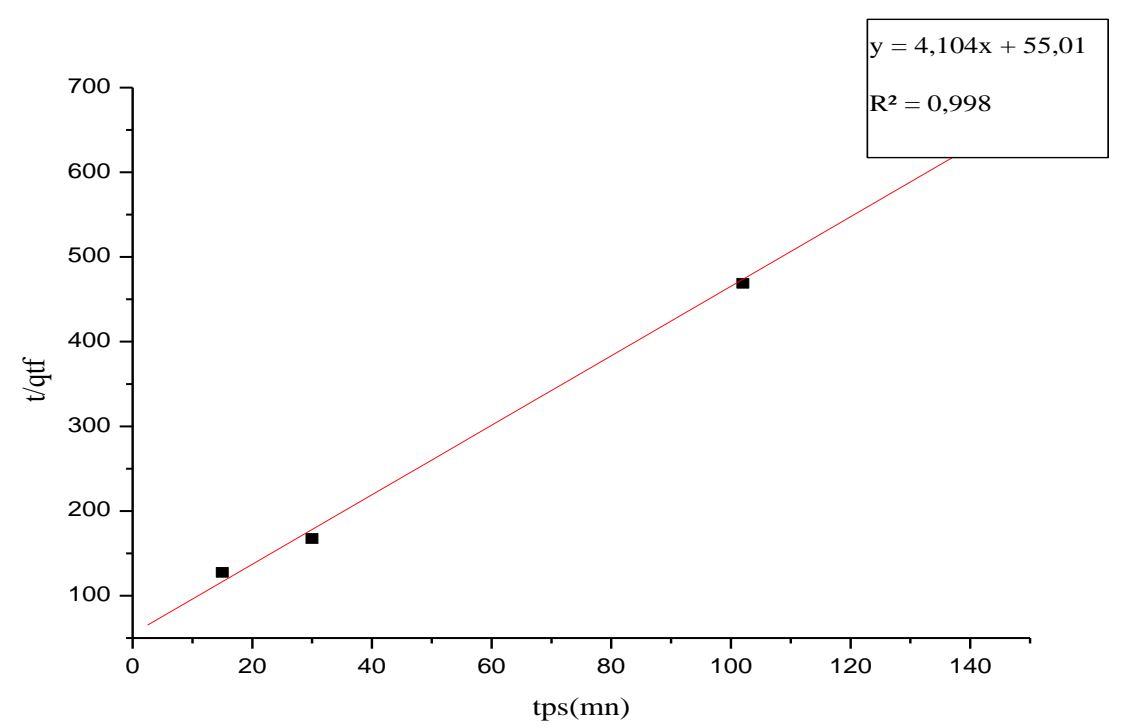

Figure 6: Linear Pseudo second order for adsorption of As (V) using CBCA

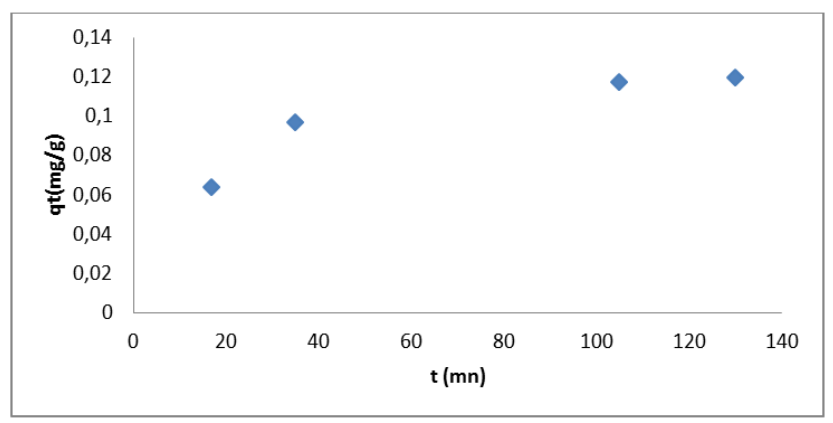

Figure7: Curve giving the amount adsorbed as a function of time. 


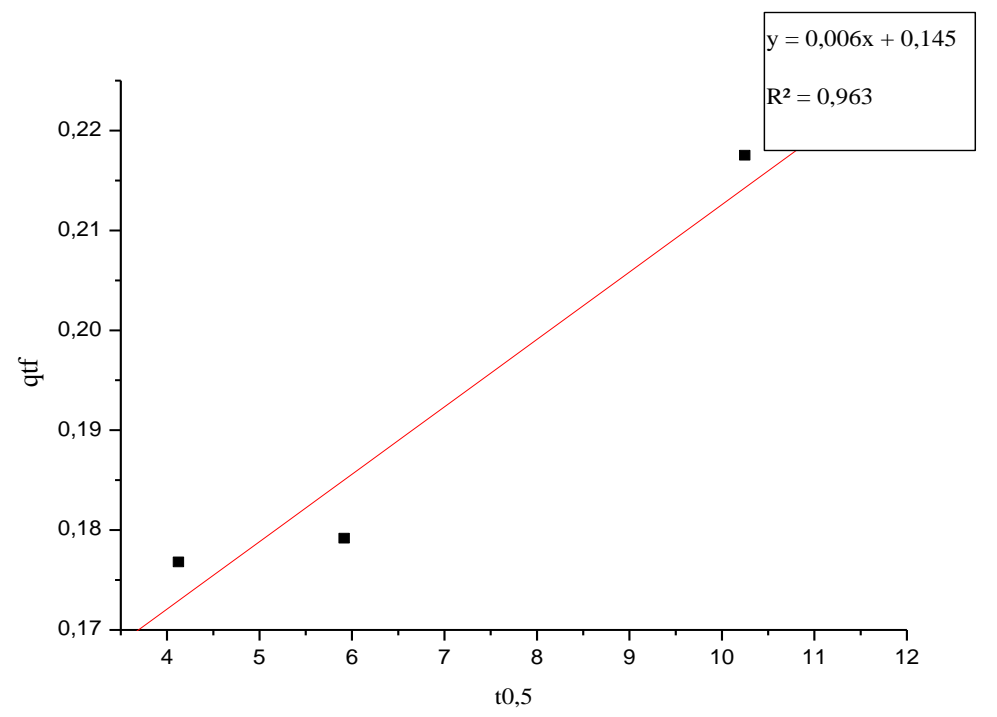

Figure 8: Intraparticle diffusion plot.

\section{DISCUSSION}

The determination of the textural parameters shows that the hull of Balanites calcined at $700{ }^{\circ} \mathrm{C}$ gave a microporous material, having a large surface area compared to certain mesoporous oxides [H. Tüysüz et al. (2012)].

The modification of the $\mathrm{O} \mathrm{H}$ vibration peaks at $3438 \mathrm{~cm}-1$ and $1190 \mathrm{~cm}-1$ before and after the adsorption Figure 2 proves the involvement of $\mathrm{O} \mathrm{H}$ in the adsorption. As shown in Figure 2, the peak observed at 3452 $\mathrm{cm}-1$ confirms the presence of a hydroxyl (OH) (Moura et al., 2012). The peak at 857 $\mathrm{cm}-1$ corresponds to the out-of-plane strain O$\mathrm{H}$ (Dharupaneedi et al., 2014). The wave number of $1272 \mathrm{~cm}^{-1}$ indicates the presence of a strong C-F bond (Zhang et al., 2007). After adsorption, the modification of the band around $1272 \mathrm{~cm}-1$ indicates that the hydroxyl groups on the adsorbent surface played a role in the adsorption. The peaks at $867 \mathrm{~cm}-1$ and $796 \mathrm{~cm}-1$ indicate that the hydrogen bond is enhanced (Raul et al., 2012). The pick at 820 $\mathrm{cm}^{-}{ }^{1}$ is attributable to an As-O stretching vibration, indicating the adsorption of As on the CBCA (Zhang et al., 2007).

The adsorption data illustrate that the Langmuir model $(\mathrm{R} 2=0.999)$ is more suitable than the Freundlich model $\left(\mathrm{R}^{2}=0.974\right)$ so the As (V) adsorption process on CBCA corresponds to a monolayer adsorption (Zhu et al., 2015). The value of $\mathrm{n}$ in the Freundlich model being greater than 1, suggests the nonlinear isotherm, which can be attributed to the heterogeneity of the adsorption site, the electrostatic attraction and other adsorbentadsorbate interactions (Zhipan Wen et al., 2014).

The rapid increase in the adsorption rate during the first 25 minutes can be explained by the large number of active sites available on the surface of the CBCA.

The correlation coefficient (R2) for the kinetic model of the pseudo-second order is greater than that of the pseudo-first order kinetic model. This indicates that the adsorption kinetics closely follow the pseudosecond order model rather than the pseudo-first order. Moreover, the value of qe, calculated from the pseudo-second-order equation is more consistent with the experimental value qe, compared to that calculated from the pseudofirst-order equation, also suggesting that the As absorption (V) follows the second order model. The slower arsenic adsorption kinetics indicates adsorption control on the surface and diffusion through the pores.

As seen in Figure 8, a sharper portion is first attributed to the diffusion of arsenic through the solution to the outer surface of the adsorbent. The second part describes the step of 
progressive adsorption, where the intraparticular diffusion is limiting. The third part indicates a very slow sorption, linked to the steric hindrance of the adsorbed molecules (Fierro et al., 2009).

The curve qt as a function of $t 0,5$ is not linear and the graph does not go through the origin. Therefore, the speed limiting process is not just intraparticular scattering. Another mechanism of intraparticular diffusion is also involved.

\section{Conclusion}

The objective of this study is the search for an effective adsorbent material for the removal of As (V) from aqueous solutions in the context of water pollution control. In this work, a new biomass adsorbent was prepared by calcination followed by activation of the Balanites Egytiacas shell (CBCA) by $\mathrm{HCl}$ for the efficient adsorption of As $(\mathrm{V})$ from an aqueous solution. The CBCA sample obtained showed performance for the removal of arsenic (As (V)) aqueous solutions. The adsorption kinetics corresponds well to the pseudo-second order nonlinear kinetic model and the adsorption isotherm data are well adapted to the nonlinear Langmuir isothermal model. Intra-particle diffusion is not the only limiting step of the adsorption process. As (V) elimination mechanisms are complex. On the basis of the experimental and theoretical results, he suggests that CBCA can be used as an effective adsorbent for the removal of As from water.

\section{COMPETING INTERESTS}

The authors declare that they have no competing interests.

\section{AUTHORS' CONTRIBUTIONS}

All authors contributed to the work and to the preparation of the manuscript.

\section{REFERENCES}

Artioli Y. 2008. Adsorption. Encyclopedia of Ecology Fath, S.E.J.D. (Ed.). Academic Press: Oxford; 60-65.

Ahmed MJK, Ahmaruzzaman M. 2016. A review on potential usage of industrial waste materials for binding heavy metal ions from aqueous solutions. J. Water Process Eng, 10: 39-47.

Ali I. 2012. New generation adsorbents for water treatment. Chem. Rev., 112: 50735091.

Andjelkovic I, Tran DNH, Kabiri S, Azari S, Markovic M, Losic D. 2015. Graphene aerogels decorated with a-FeOOH nanoparticles for efficient adsorption of arsenic from contaminated waters. ACS Appl. Mater. Interfaces, 7: 9758-9766.

Chandra V, Park J, Chun Y, Lee J W, Hwang IC, Kim KS. 2010. Water-Dispersible Magnetite-Reduced Graphene Oxide Composites for Arsenic Removal. J. American Chemical Society, 4: 39793686.

Emsley J. 2001. Nature's Building Blocks: An $A-Z$ Guide to the Elements. University Press: Oxford.

Fierro V, Mũniz G, Gonzalez-Sanchez G. 2009. Arsenic removal by irondopedactivated carbons prepared by ferric chloride forced hydrolysis. $J$. Hazard. Mater, 168: 430-437.

Ghanizadeh G, Ehrampoush MH, Ghaneian MT. 2010. Application of ironimpregnated activated carbon for removal of arsenic from water, Iran J.Environ. Health Sci. Eng, 7: 145-156.

Guo H, Ren Y, Liu Q, Zhao K, Li Y. 2012. Enhancement of arsenic adsorption during mineral transformation from siderite to goethite. Environ. Sci. Technol, 47: 1009-1016.

Hameed BH, Tan IAW, Ahmad AL. 2008. Adsorption isotherm, kinetic modeling and mechanism of 2,4,6-trichlorophenol on coconut husk-based activated carbon. Chem. Eng. J, 144: 235-244.

Kavitha D, Namasivayam C. 2007. Experimental and kinetic studies on methylene blue adsorption by coir pith Carbon. Bioresour. Technol, 98: 14-21.

Kumar D. 2011. Chemical reaction-and particle diffusion-based kinetic modeling 
ofmetal biosorption by a phormidium spdominated cyanobacterial mat. Bioresour. Technol, 102: 633-640.

Ling-LiMin, Zhi-HuaYuan, Lu-BinZhong, QingLiu, Ren-XiangWu. 2015. Preparation of chitosan based electrospun nanofiber membrane and its adsorptive removal of arsenate from aqueous solution. Chemical Engineering Journal, 267: 132-141.

Luo XB, Wang CC, Luo SL, Dong RZ, Tu XM, Zeng GS. 2012. Adsorption of As (III) and As (V) from water using magnetite Fe3O4-reduced graphite oxide$\mathrm{MnO}_{2}$ nanocomposites. Chem. Eng. J, 187: 45-52.

Ma L, Zhang WX. 2008. The technical and economic feasibility of iron shavings is evaluated in a series of experiments from benchtop to full-scale facility. Environ. Sci. Technol, 42: 53845389.

Saha S, Sarkar P. 2012. Arsenic remediation from drinking water by synthesized nanoalumina dispersed in chitosan-grafted polyacrylamide, $J$. Hazard. Mater, 227: 68-78.

Salameh Y, Albadarin AB, Allen S, Walker G, Ahmad M N M. 2015. Arsenic (III, V) adsorption onto charred dolomite: charring optimization and batch studies, Chem. Eng. J, 259: 663-671.

Schüth. 2012. Synthesis of Hard Magnetic Ordered Mesoporous $\mathrm{Co}_{3} \mathrm{O}_{4} / \mathrm{CoFe}_{2} \mathrm{O}_{4}$ Nanocomposites. Chem. Mater, 24: 2493-2500.

Shan C, Tong M. 2013. Arsenic removal by nanoparticles. Water Res, 47: 34113421.

Sparks D L. 2007. Kinetics of Soil Chemical Processes. Academic Press, Inc., New York, Technol, 41: 4613-4619.
Yang R, Su Y, Aubrecht KB, Wang X, Ma HG, Grubbs RB, Hsiao BS, Chu B. 2015. Thiol-functionalized chitin nanofibers for As (III) adsorption, Polymer, 60: 9-17.

Zainab ZI, Hala NA. 2015. Sustainable approach for recycling waste lamb and chicken bones for fluoride removal from water followed by reusing fluoridebearing waste. Waste Management, 45: 66-75.

Zhang GS, Qu JH, Liu HJ, Liu RP, Li GT. 2007. Removal mechanism of As (III) by a novel Fe-Mn binary oxide adsorbent: oxidation and sorption. Environ. Sci. Technol, 41: 4613-4619.

Zhang GS, Qu JH, Liu HJ, Liu RP, Li GT. 2011. Removal mechanism of As (III) by a novel Fe-Mn Binary Oxide adsorbent: oxidation and sorption. Environ. Sci, 379: 116-120.

Zhipan W, Yalei Z, Chaomeng D, Bo C, Sujin G, Hong Y, Deli W. 2014. Synthesis of ordered mesoporous iron manganese bimetal Oxides for arsenic removal from aqueous solutions. Microporous and Esoporous Materials, 200: 235-244.

Zhu J, Baig SA, Sheng TT, Lou Z, Wang ZX, $\mathrm{Xu} \quad \mathrm{XH}$. 2015. Fe3O4and $\mathrm{MnO} 2$ assembled on Honeycomb briquette cinders (HBC) for arsenic removal fromaqueous solution. J. Hazard. Mater, 286: 220-228. 